\title{
Preparation of Bruch's membrane and analysis of the age-related changes in the structural collagens
}

Wojciech S S Karwatowski,Tracy E Jeffries, Victor C Duance, Julie Albon, Allen J Bailey, David L Easty

\begin{abstract}
Aims/Background-The morphological changes in Bruch's membrane and its constituent collagen seen during aging have been studied extensively but the chemical nature of the collagen and any aging changes have not previously been evaluated.
\end{abstract}

Methods-A method for preparing purified Bruch's membrane from human cadaver eyes by dissection preceded by trypsin digestion was developed. Following pepsin digestion, the constituent collagens were analysed by SDSPAGE and by immunoblotting. Cyanogen bromide digestion was used to ascertain the solubility of the collagen and the proportion of type I to type III collagen. After hydrolysis of Bruch's membrane samples the constituent amino acids and collagen crosslinks were measured.

Results-The presence of collagen types I, III, IV, and V in Bruch's membrane was confirmed. The proportion of type III collagen as a percentage of total fibrous collagens was calculated as being between $35 \%$ and $39 \%$, with no significant difference between different macular and peripheral sites or with age. There was a highly significant decline in the solubility of Bruch's membrane collagen with age, from near $100 \%$ in the first decade of life to $40-50 \%$ in the ninth decade at both macular and peripheral sites. There was no significant change in the amount of enzymatically formed collagen crosslinks with age. Amino acid analysis indicated a significant increase in the amount of noncollagen protein with age in macular but not peripheral sites.

Conclusion-Changes in the constituent collagens may contribute to the accumulation of debris in Bruch's membrane with age and interfere with the function of the retinal pigment epithelium, with subsequent consequences for the overlying photoreceptors.

(Br F Ophthalmol 1995; 79: 944-952)

The high incidence of age-related macular degeneration (ARMD) and its significant impact on the visual function in the elderly population has led to considerable interest in the function and relations of the photoreceptors, the retinal pigment epithelium (RPE), and its adjacent structures, in particular Bruch's membrane. Their failure to function normally is critical in the pathological process that leads to the development of ARMD, and the changes that occur in these tissues with age and in the disease process are of relevance to our understanding of ARMD.

In aging and ARMD considerable morphological changes are seen in Bruch's membrane. Changes include the deposition of material between the RPE and its basement membrane. Drusen, which are focal, lie between the RPE basement membrane and the inner collagenous zone of Bruch's membrane. ${ }^{1-3}$ More diffuse changes are also seen, with the deposition of debris, vesicular material, and membrane coated bodies within Bruch's membrane, especially in the inner collagenous zone. ${ }^{4}$ This material has a high lipid content but its composition appears to vary between individuals. ${ }^{5}$ It is believed to originate in the photoreceptor outer segments and to be the product of RPE metabolism. ${ }^{6-9}$ Although the morphological changes that occur in aging and their nature are well described, the mechanism by which the material is retained in the matrix of the membrane is not understood, nor are the consequences of this deposition process. ${ }^{10}$

The structure of Bruch's membrane depends on the integrity of collagen fibres and concurrent with the macroscopic changes there appear to be age-related changes in the nature of the collagen. There is an increased number of striated collagen fibres present in both the inner and outer collagenous layers with increasing age. This $64 \mathrm{~nm}$ banded material is assumed to be the fibrillar type I collagen. This is accompanied by the deposition of short segments of a $100 \mathrm{~nm}$ banded form which is assumed to be collagen type VI. ${ }^{2811}$ The distribution of the collagen types in Bruch's membrane has been studied with immunohistochemical techniques ${ }^{12} 13$ which demonstrated the presence of types I, III, IV, and V collagen. The staining for types IV and $V$ appeared to be bilaminar, below the RPE and around the choriocapillaris, while that for types I and III tended to be diffuse throughout the thickness of the membrane. In older tissue there appeared to be increased immunostaining for type I collagen as well as frequent interruptions in the bilaminar staining pattern for types IV and V collagen. Significantly, these interruptions were not always associated with drusen. ${ }^{12}$ Electron microscopic studies with immunogold have confirmed the presence of types I, III, and V collagen in the matrix and have shown that type IV is located in the basement membrane of the RPE and choriocapillaris. Type VI collagen was shown to be present and related to the central elastic lamina of the membrane. ${ }^{1415}$ \\ 15 June 1995
}



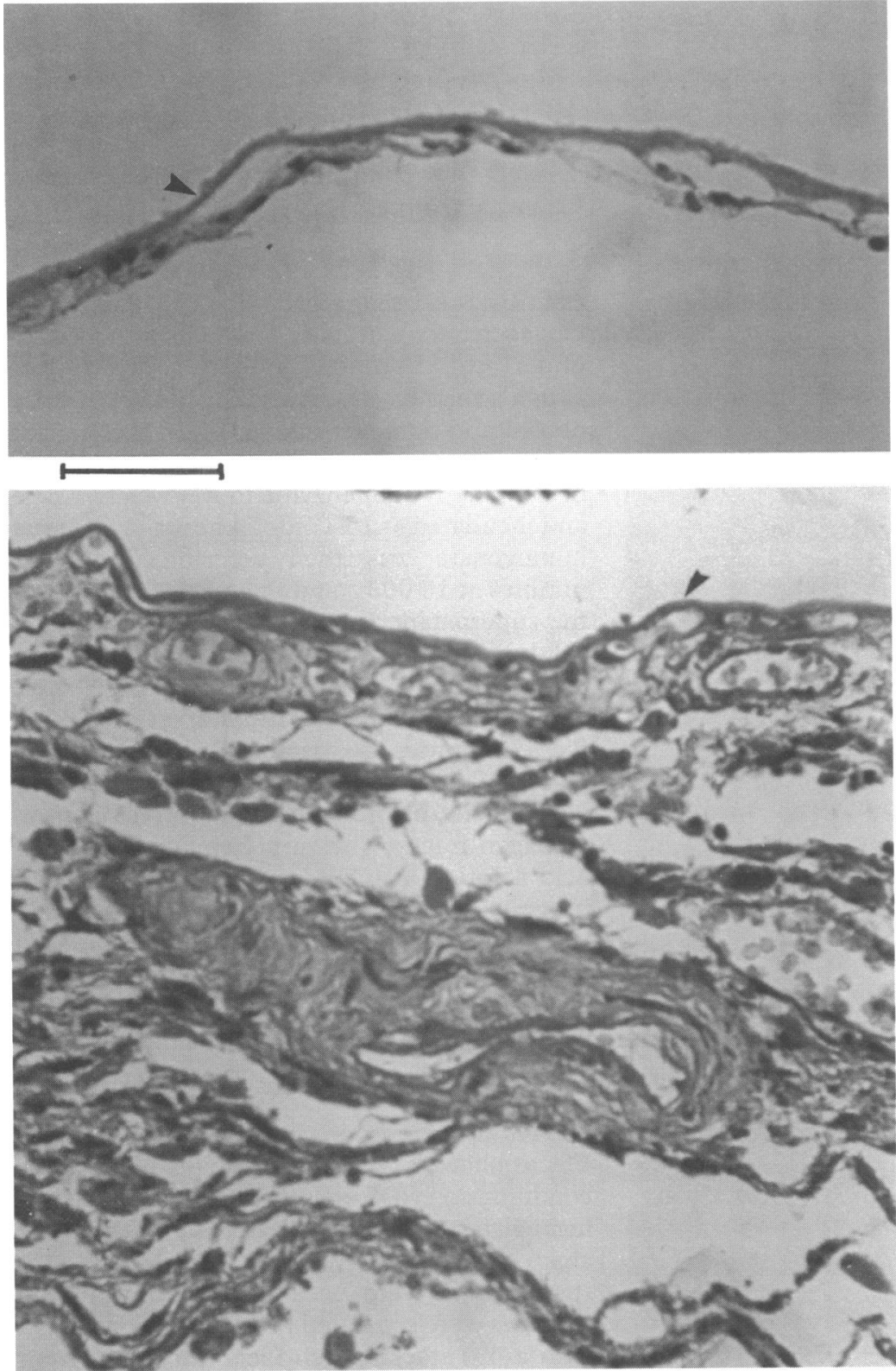

Figure 1 Light micrographs showing retinal pigment epithelium (RPE), Bruch's membrane (arrowhead) and choroid before treatment and dissection (bottom). After trypsin digestion and dissection the RPE is completely removed as well as the bulk of choroidal tissue (top). Scale bar $=100 \mu \mathrm{m}$. macular area inspected for gross pathological abnormalities. Those eyes with visible pathology were discarded. The eye cup was then taken and a $7 \mathrm{~mm}$ trephine used to punch out a chorioretinal disc. The disc was either centred on the fovea (so called macular area) or it was taken from the periphery posterior to the ora serrata to include the equatorial region. These discs were removed from the eye and the neuroretina peeled off from the underlying pigment epithelium. The choroid-Bruch's membrane-RPE complex was then removed from the underlying sclera.

Initial attempts using established methods ${ }^{16-18}$ for dissecting the choroidal tissue from Bruch's membrane proved difficult and ineffective. A different approach was therefore used in an attempt to make the dissection process easier and to reproducibly yield purer tissue. The tissue complex was incubated in a $0.01 \%$ solution of trypsin in a $10 \mathrm{mM}$ sodium phosphate buffer $\mathrm{pH} 7 \cdot 4$ for 10 minutes at $37^{\circ} \mathrm{C}$ and subsequently rinsed in $10 \mathrm{mM}$ sodium phosphate buffer $\mathrm{pH} 7 \cdot 4$. The tissue was then dissected using a glass rod and fine forceps to remove the choroidal tissue. During this process the tissue was mounted on moistened hardened filter paper (Whatman No 2) to immobilise it. This fixation had the effect of removing the RPE. Any RPE remaining after this process was removed by rubbing gently with a glass rod and rinsing away with buffer. Using this process it proved possible to produce pieces of dissected Bruch's membrane which were clear of most choroidal tissue and RPE.

The efficacy and suitability of this process was assessed using three criteria. The amount of choroid removed by the preparative process was assessed by histology. The degree to which the basement membrane of the retinal pigment epithelium was left intact after tissue preparation was inspected by scanning electron microscopy. Any loss of collagen during trypsin incubation was determined by hydroxyproline analysis of the incubation supernatant.

In view of these morphological and immunohistochemical changes, we have developed a method for the preparation of sufficient quantities of Bruch's membrane and carried out a biochemical analysis of the agerelated changes.

\section{Materials and methods}

\section{MATERIALS}

Tissue was obtained from the United Kingdom Transplant Service Eye Bank at the Bristol Eye Hospital. Cadaver eyes were obtained soon after removal of the corneoscleral disc. Eyes with a known history of eye disease or from donors with diabetes mellitus were excluded.

PREPARATION OF BRUCH'S MEMBRANE

The iris lens diaphram was removed and the

\section{LIGHT MICROSCOPY}

Tissue specimens for light microscopy were cacodylate buffer $\mathrm{pH} 7 \cdot 2$ for 2 hours, rinsed twice in cacodylate buffer, and then divided before being dehydrated in serial alcohols, mounted in paraffin wax, and sectioned. Sections were stained with haematoxylin and eosin.

Samples for scanning electron microscopy were prepared by fixing as above. The sample tuted with amyl acetate. The tissue was then subjected to critical point drying under carbon dioxide before being mounted on stubs and sputter coated with gold. The samples were examined in a Cambridge Instruments Stereoscan 200 scanning electron microscope. fixed in $2 \cdot 5 \%$ glutaraldehyde in sodium

\section{SCANNING ELECTRON MICROSCOPY} was dehydrated in serial alcohols and substi- 


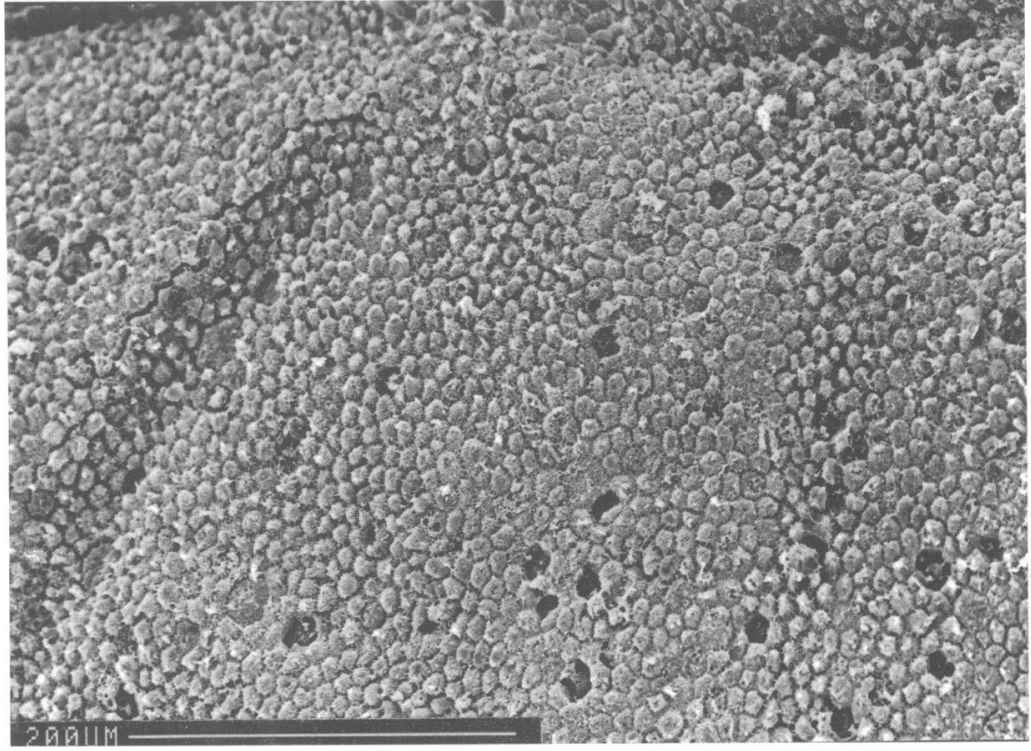

Fig $2 A$

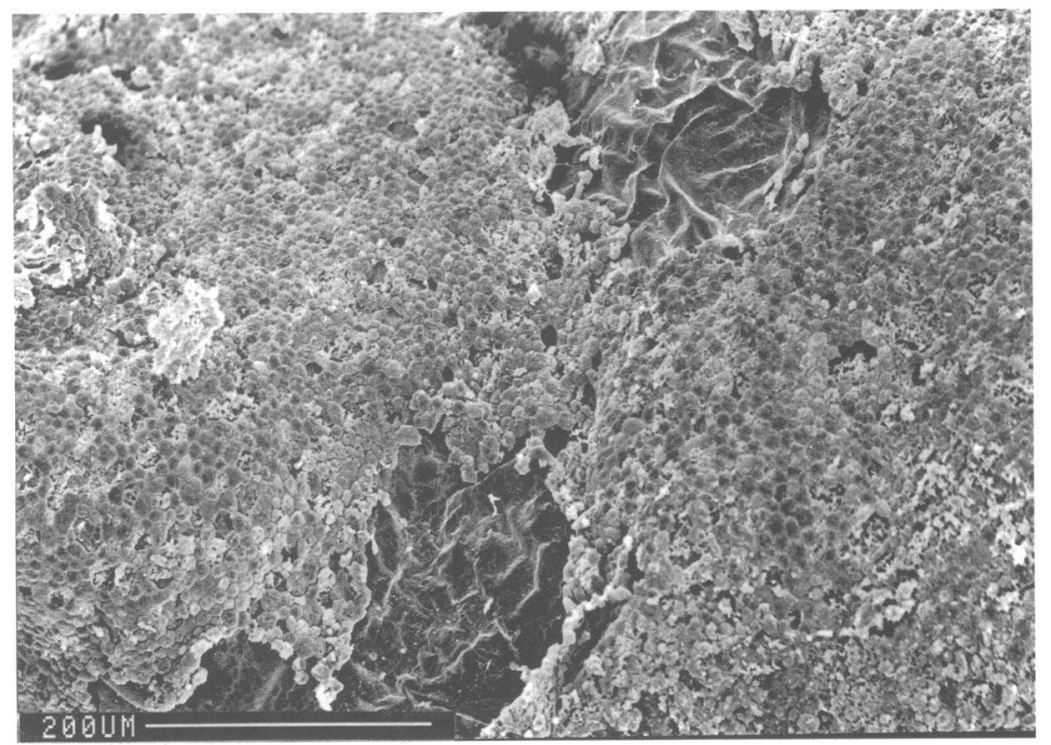

Fig $2 B$

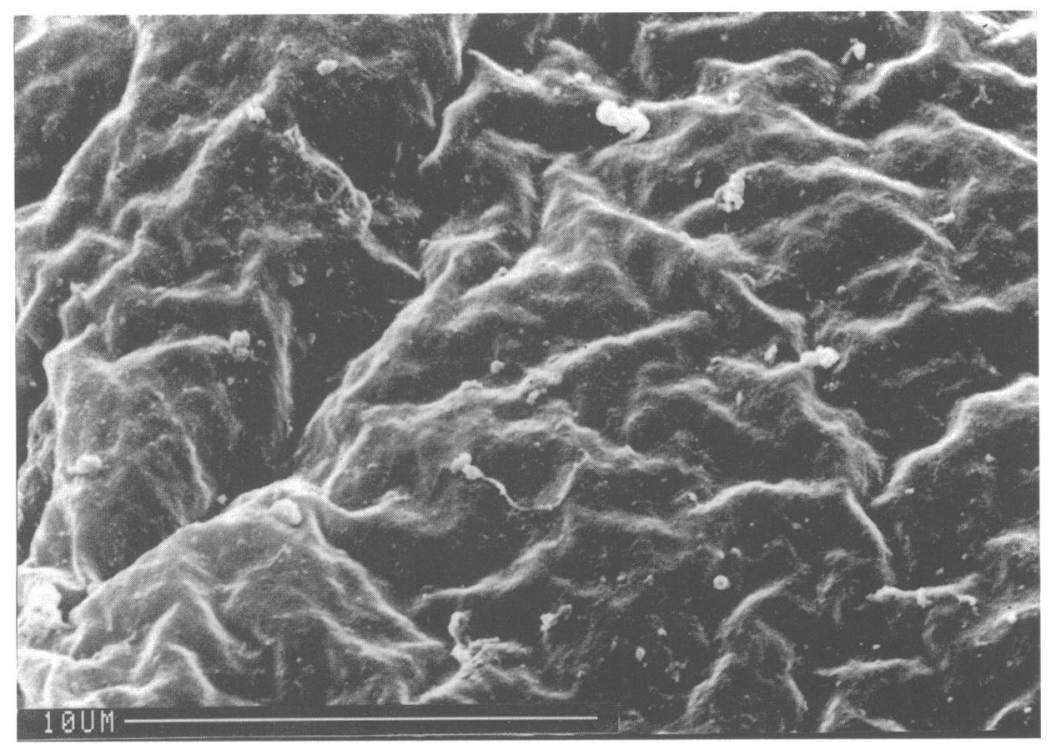

Fig $2 \mathrm{C}$

Figure 2 Scanning electron micrograph showing an intact retinal pigment epithelium (RPE) layer before incubation $(A)$. After incubation in trypsin the RPE remains almost completely intact (B). Subsequent dissection leaves the basement membrane of the RPE essentially intact $(C)$.
HYDROXYPROLINE ASSAY

Dried samples for hydroxyproline assay were hydrolysed in $6 \mathrm{M} \mathrm{HCl}$ at $115^{\circ} \mathrm{C}$ for 24 hours. After drying, the hydrolysates were dissolved in distilled water and the hydroxyproline content assayed by colorimetric reaction using a ChemLab Autoanalyser.

\section{COLLAGEN PREPARATION}

Collagen was extracted from prepared tissue under acid conditions by pepsin digestion. ${ }^{19}$ Bruch's membranes from 20 whole eyes were pooled and homogenised in $0.5 \mathrm{M}$ acetic acid; pepsin (Sigma Chemicals) was added in a ratio of 1:50 dry weight enzyme to wet weight tissue and incubated at $15^{\circ} \mathrm{C}$ for 24 hours. The tissue homogenate was then centrifuged for 45 minutes at $16000 \mathrm{~g}$ and the soluble collagen in the supernatant precipitated by slowly adding solid sodium chloride to raise the molarity of the solution to $2.0 \mathrm{M} \mathrm{NaCl}$. The precipitate was harvested by centrifuging at $16000 \mathrm{~g}$ for 45 minutes, redissolved in $0.5 \mathrm{M}$ acetic acid, and dialysed extensively against $0.5 \mathrm{M}$ acetic acid before differential precipitation. Collagen fractions were precipitated from the acid solution at $0.7 \mathrm{M}$ and $1.2 \mathrm{M} \mathrm{NaCl}$ and harvested as above. Precipitates were dialysed extensively against $0.5 \mathrm{M}$ acetic acid and then freeze dried before analysis by sodium dodecyl sulphate-polyacrylamide gel electrophoresis (SDS-PAGE).

SDS-PAGE

Electrophoresis was carried under denaturing conditions on SDS-polyacrylamide gels according to the method of Laemmli. ${ }^{20}$ For whole chain collagens a $6 \%$ resolving gel and a $4 \%$ stacking gel were used. Cyanogen bromide peptides were separated on a $10 \%$ resolving gel with a $4 \%$ stacking gel. Gels were run on an LKB electrophoresis system at a constant current of $40 \mathrm{~mA} / \mathrm{gel}$ or on a Mighty Micro Minigel system at $15 \mathrm{~mA} / \mathrm{gel}$. Gels were stained with $0.005 \%$ Coomassie Blue $R$ in $10 \%$ methanol, $7 \cdot 5 \%$ acetic acid in water and destained in $10 \%$ methanol and $7.5 \%$ acetic acid in water.

Samples for electrophoresis were dissolved in sample buffer ( $2 \%$ SDS, TRIS $0.125 \mathrm{M}$, glycerol $10 \%$ with bromophenol blue) at a concentration of $5-10 \mathrm{mg} / \mathrm{ml}$. The samples were denatured by heating to $60^{\circ} \mathrm{C}$ for 20 minutes. Samples run under reducing conditions were made up to $5 \%$ mercaptoethanol.

IMMUNOBLOTTING

Samples for immunoblotting were run on $7.5 \%$ SDS-polyacrylamide gels on a Pharmacia Phast Gel system. The proteins were transferred onto Immobilon-P membrane by diffusion. The membrane was blocked with $4 \% \mathrm{w} / \mathrm{v}$ skimmed milk powder in a $10 \mathrm{mM}$ TRIS/HCl buffer pH $7 \cdot 4$ with $0 \cdot 15 \mathrm{M} \mathrm{NaCl}$ for 30 minutes and then washed in rinsing buffer, $10 \mathrm{mM}$ TRIS/ $\mathrm{HCl} \mathrm{pH} \mathrm{7.4,} 0.5 \mathrm{M}$ $\mathrm{NaCl}, 0.5 \%$ Tween 20 , for 30 minutes. 
Figure 3 Separation of collagen fractions on SDS-PAGE. (Left)

Separation of $0.7 \mathrm{M}$

fraction reduced and unreduced showing presence of types I and III collagen. (Centre) $1 \cdot 2 M$ fraction showing the presence of type $V$ collagen as the $\alpha 1 \alpha 2 \alpha 3$ isomer. (Right) Cyanogen bromide of Bruch's

membrane collagen showing the presence of $C B$ peptides from types I and III

collagen.
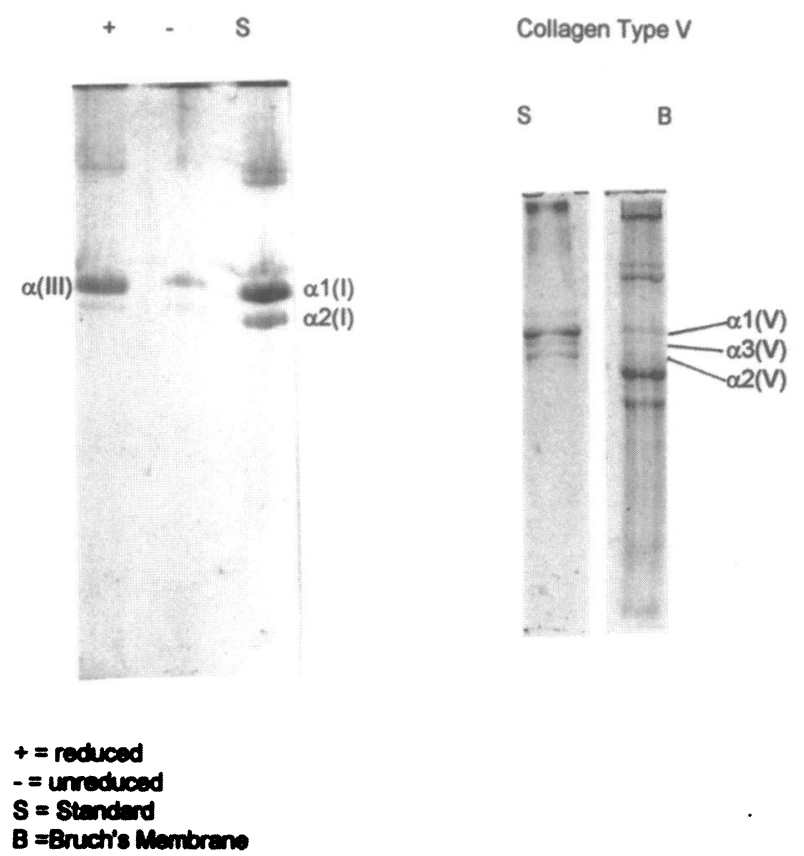

$a=$ Standard

$b=$ Bruch's Membrane
Primary antibody was applied at a dilution of $1: 1000$ in antibody buffer, $10 \mathrm{mM}$ TRIS $/ \mathrm{HCl}$ pH $7 \cdot 4,0.15 \mathrm{M} \mathrm{NaCl}, 0 \cdot 1 \%$ Tween 20 , for $2 \frac{1}{2}$ hours at room temperature. The membrane was washed extensively with rinsing buffer and then incubated with secondary antibody conjugated to alkaline phosphatase at a dilution of $1: 1000$ in antibody buffer with the addition of $4 \% \mathrm{w} / \mathrm{v}$ skimmed milk powder for $1 \frac{1}{2}$ hours. After extensive washing with distilled water and $0 \cdot 1 \mathrm{M} \mathrm{MgCl}_{2}$ /TRIS buffer the colour reaction was developed with 5-bromo-4-chloro-3-indolyl phosphate and nitro blue tetrazolium in $0 \cdot 1 \mathrm{M} \mathrm{MgCl}_{2} /$ TRIS (Sigma Chemicals) buffer. The reaction was stopped by washing the membrane in distilled water. The membrane was air dried before photography on Kodak Tech Pan film.

Primary antibodies were polyclonal goat antibodies against collagen types I, III, IV, and V (Southern Biotechnologies) and polyclonal rabbit antibody against collagen type VI (Chemicon International). The alkaline phosphatase conjugated secondary antibodies, against goat and rabbit immunoglobulins, had previously been adsorbed against human serum proteins (Sigma Chemicals).

\section{SOLUBILITY AFTER CYANOGEN BROMIDE}

CLEAVAGE

Tissue samples were freeze dried and delipidated in 2:1 chloroform:methanol mixture. The samples were reduced in $10 \mathrm{mM}$ dithiothreitol (DTT) to reduce methionine sulphoxide to sulphydryl to ensure complete cleavage of the peptide chains by the cyanogen bromide. The samples were reacted with cyanogen bromine in $70 \%$ formic acid at room temperature for 18 hours. The reaction was stopped by the addition of three times the reaction volume of water and any undissolved tissue removed. Both supernatant and tissue residue were freeze dried and analysed for hydroxyproline content. The proportion of collagen solubilised from the tissue was calculated as the proportion of total hydroxyproline that was in solution.

\section{TYPE I TO TYPE III COLLAGEN RATIOS}

The relative proportion of type I to type III collagen present in the tissue was determined from the ratio of the 1 (I)CB 8 and 1 (III)CB5 peptides using the method described by Light. ${ }^{21}$ Tissue was prepared and digested as described above from the macular and peripheral regions of donor eyes. The supernatant from the digestion was freeze dried and the resulting sample dissolved in electrophoresis sample buffer and separated on $10 \%$ SDSpolyacrylamide gels and stained with Coomassie Blue R. After extensive destaining the gels were scanned on an LKB Ultrascan $\mathrm{XL}$ enhanced laser densitometer and the results analysed using LKB 2400 Gelscan XL software.

\section{AMINO ACID COMPOSITION}

Bruch's membrane discs were prepared as described above and hydrolysed in $0.5 \mathrm{ml} 6 \mathrm{M}$ $\mathrm{HCl}$ under nitrogen at $115^{\circ} \mathrm{C}$ for 20 hours. The resulting hydrolysate was dried under vacuum and analysed on an LKB 4400 AutoAnalyser (Pharmacia).

\section{COLLAGEN CROSSLINK ANALYSIS}

Bruch's membrane was suspended in phosphate buffered saline $\mathrm{pH} 7 \cdot 4$, and reduction of the immature reducible cross links achieved using $\mathrm{NaBH}_{4}$ as described previously. ${ }^{22}$ An aliquot was removed for hydroxyproline analysis and the rest of the sample was fractionated on a 
Figure 4 Immunoblots showing the presence of types I, III, IV, and V collagen.
Type I

B S

B S
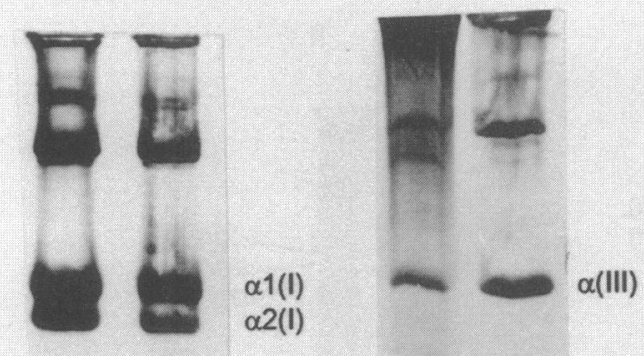

B $=$ Bruch's Membrane Extract

$\mathrm{S}=$ Standard

CF-1 column in butan-1-ol, glacial acetic acid, and water (4:1:1). Crosslinking amino acids were recovered from the CF-1 columns with water and analysed on an LKB 4400 AutoAnalyser (Pharmacia) as recently described in detail by Sims and Bailey. ${ }^{23}$

\section{Results}

\section{TISSUE ASSESSMENT}

Bruch's membrane produced by the method described above allowed the complete removal of the RPE as assessed by light microscopy. The choroidal tissue was removed by dissection leaving only Bruch's membrane and choriocapillaris (Fig 1).

Scanning electron microscopy was used to assess the condition of the basement membrane. Removal of the neuroretinal tissue shows an almost intact RPE (Fig 2A). Incubation of the tissue in trypsin causes small areas of the RPE to be washed off, revealing areas of basement membrane (Fig 2B).

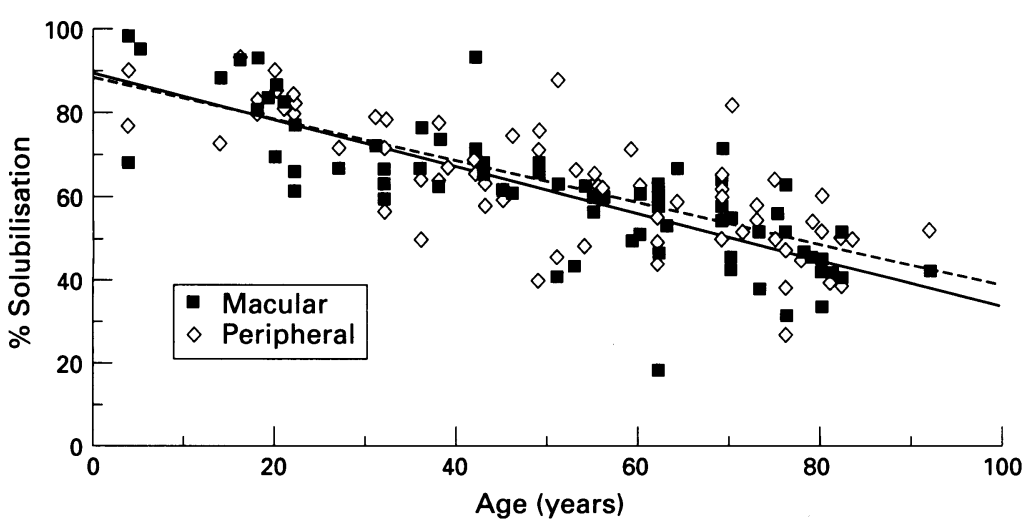

Figure 5 Cyanogen bromide solubility of Bruch's membrane collagen. There is a significant decline with age $(p<0 \cdot 001)$. This is similar in both macular and peripheral tissue.
Dissection of the tissue subsequent to trypsin incubation resulted in the removal of most of the debris from the basement membrane leaving only Bruch's membrane and some choriocapillaris. The basement membrane itself remained intact (Fig 2C). Only a small amount of collagen $(4.4 \%)$ was released during the incubation with trypsin. Prepared tissue discs had a dry weight of between 50 and $100 \mathrm{~g}$.

COLLAGEN OF BRUCH'S MEMBRANE

The yield of collagen from the solubilisation with pepsin in $0.5 \mathrm{M}$ acetic acid was between $10 \%$ and $15 \%$ of total collagen. Samples of collagen from salt precipitations were analysed by SDS-PAGE under both reducing and nonreducing conditions. This showed the presence of type I and III collagen in the $0.7 \mathrm{M}$ sodium chloride in $0.5 \mathrm{M}$ acetic acid precipitate (Fig 3). Reduction of this fraction causes an increase in the density of the $\alpha 1$ (I) band as the human $\alpha$ (III) band comigrates with it. There was no evidence of type IV collagen on these gels. The $1.2 \mathrm{M}$ fraction showed the presence of type $\mathrm{V}$ collagen as well as some contaminating type I. The isoform of type $V$ collagen present appears to be $\alpha 1(\mathrm{~V}), \alpha 2(\mathrm{~V}), \alpha 3(\mathrm{~V})$ (Fig 3).

Immunoblotting for the various collagen types revealed the presence of collagen types I, III, IV and V (Fig 4). The type IV collagen peptides revealed by immunoblotting are those that are usually seen by SDS-PAGE after extensive digestion with pepsin. ${ }^{24} \mathrm{We}$ were unable to identify type VI collagen in any of our preparations.

CYANOGEN BROMIDE SOLUBILISATION

The solubility of Bruch's membrane (76 eyes) decreased from near $100 \%$ at 1 year of age to 


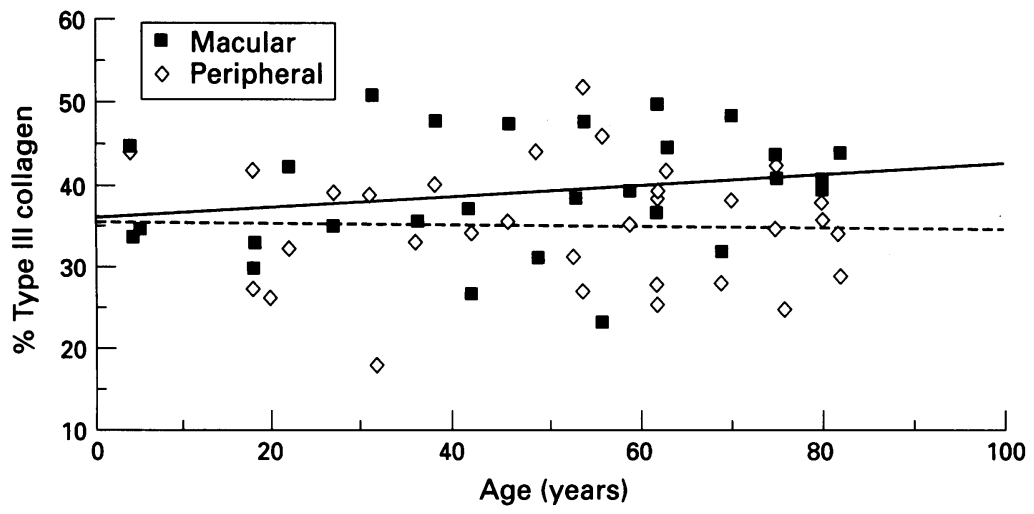

Figure 6 Proportion of type III collagen as a percentage of total fibrous collagen (types I and III) in both macular and peripheral tissue. There is no significant difference with age or between the two areas.
$40-50 \%$ in the ninth decade of life. This decline in solubility was seen in both macular and peripheral tissue and was highly significant $(p<0.001)$. There was no significant difference between macular and peripheral tissue (Fig 5). Cyanogen bromide peptide gels demonstrated the relative amounts of types I and III collagens in the membrane (Fig 3). The proportion of type III based on 50 samples of Bruch's membrane was calculated as $39 \%$ in the macular tissue and $35 \%$ in the peripheral tissue. There was no significant change with age in these values (Fig 6).

\section{AMINO ACID COMPOSITION}

The total amino acid composition of samples of Bruch's membrane from a range of ages and from macular and peripheral areas of the eye was determined. The level of hydroxyproline in macular tissue was significantly higher than in the periphery $(p=0 \cdot 014)$. However, the proportion of hydroxyproline in the macular Bruch's membrane declined with age $(p=0.044)$ while that of peripheral tissue remained unchanged (Fig 7). There was a significant increase in the proportion of tyrosine, methionine and phenylalanine, amino acids low in collagen, to total amino acids with age in the macular tissue $(p<0.01)$ (Figs 8A, B, C). An increase in the proportion of these amino acids was also seen in peripheral tissue but this was not statistically significant.

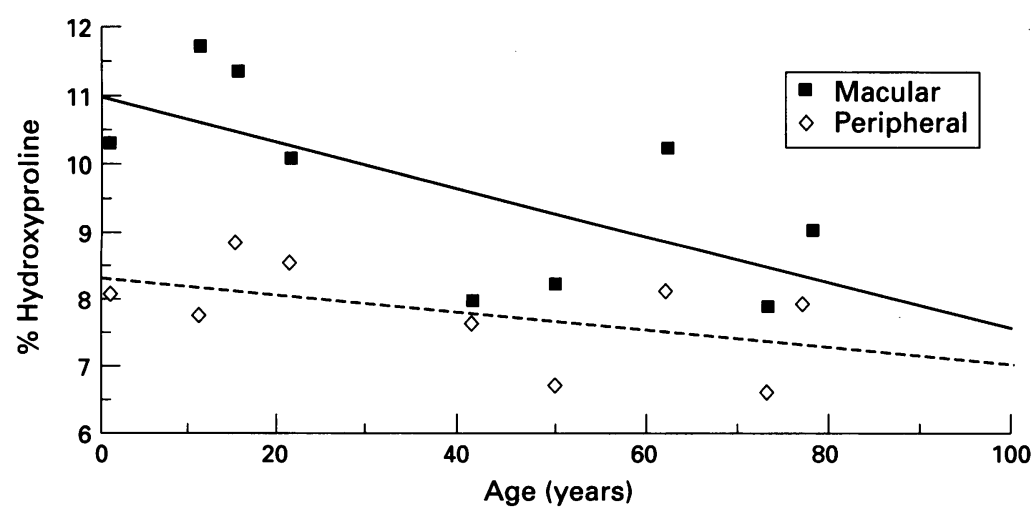

Figure 7 Proportion of hydroxyproline to total amino acids in Bruch's membrane from macular and peripheral regions as a function of age.

\section{CROSSLINKS}

Analysis of the profile of collagen crosslinks from 41 tissue samples of age from less than 1 year to 94 years, failed to show the presence of any of the immature reducible crosslinks, dehydro-hydroxylysinonorleucine and hydroxylysino-ketonorleucine. The mature collagen crosslink hydroxylysyl-pyridinoline was shown to be present at levels of up to $0.4 \mathrm{moles} / \mathrm{mole}$ of collagen but there was no significant change in crosslink level with age (Fig 9). The mature crosslink histidino-hydroxylysinonorleucine was not detected in the samples. An unknown chromatographic peak in the 'crosslink' region of the chromatogram showed a molar rise in concentration with age (Fig 10). The ninhydrin positive reaction of this compound indicated that it was an amino acid.

\section{Discussion}

The removal of the RPE by the preparative process, of prior incubation in trypsin followed by dissection, is not unexpected as RPE is easily harvested for cell culture ${ }^{25}$ and our method amounts to an extension of the standard harvesting method. The more significant finding is that the vast bulk of choroidal tissue is removed by our method (Fig 1). This advantage is further reinforced by the ease of dissection of the choroid following trypsin incubation. The appearance of Bruch's membrane after trypsin incubation and dissection compares favourably with the only published micrograph of prepared Bruch's membrane. ${ }^{18}$

Scanning electron microscopy shows that the basement membrane of the RPE remains largely intact following preparation (Fig 2C). Published scanning electron micrographs ${ }^{26}$ show fine projections from the basement membrane that form the interdigitations of the basement membrane with the RPE that are seen in transmission electron micrographs. ${ }^{3}$ In our scanning electron microscopy preparations we were unable to observe these projections perhaps because they were removed by a combination of trypsin digestion and physical trauma during the dissection process.

The small amount of collagen released during trypsin incubation could not have arisen from the RPE side of the tissue as the RPE remains mostly intact after incubation (Fig 2B). Thus the collagen released must have come from the choroidal side of the tissue and is therefore unlikely to be of any significance as that tissue is subsequently removed by the dissection process.

Thus, the tissue preparation we have developed is capable of producing a significant amount of purified Bruch's membrane in which the choroid is removed and the basement membrane of the RPE is left intact.

The collagen types present in Bruch's membrane have been demonstrated by SDS-PAGE, immunoblotting, and cyanogen bromide digestion techniques, as collagen types I, III, IV, and V. Previous studies have indicated the presence of these collagens by immunohistological staining. ${ }^{12} 13 \mathrm{We}$ were unable to confirm the presence of collagen type VI, which 

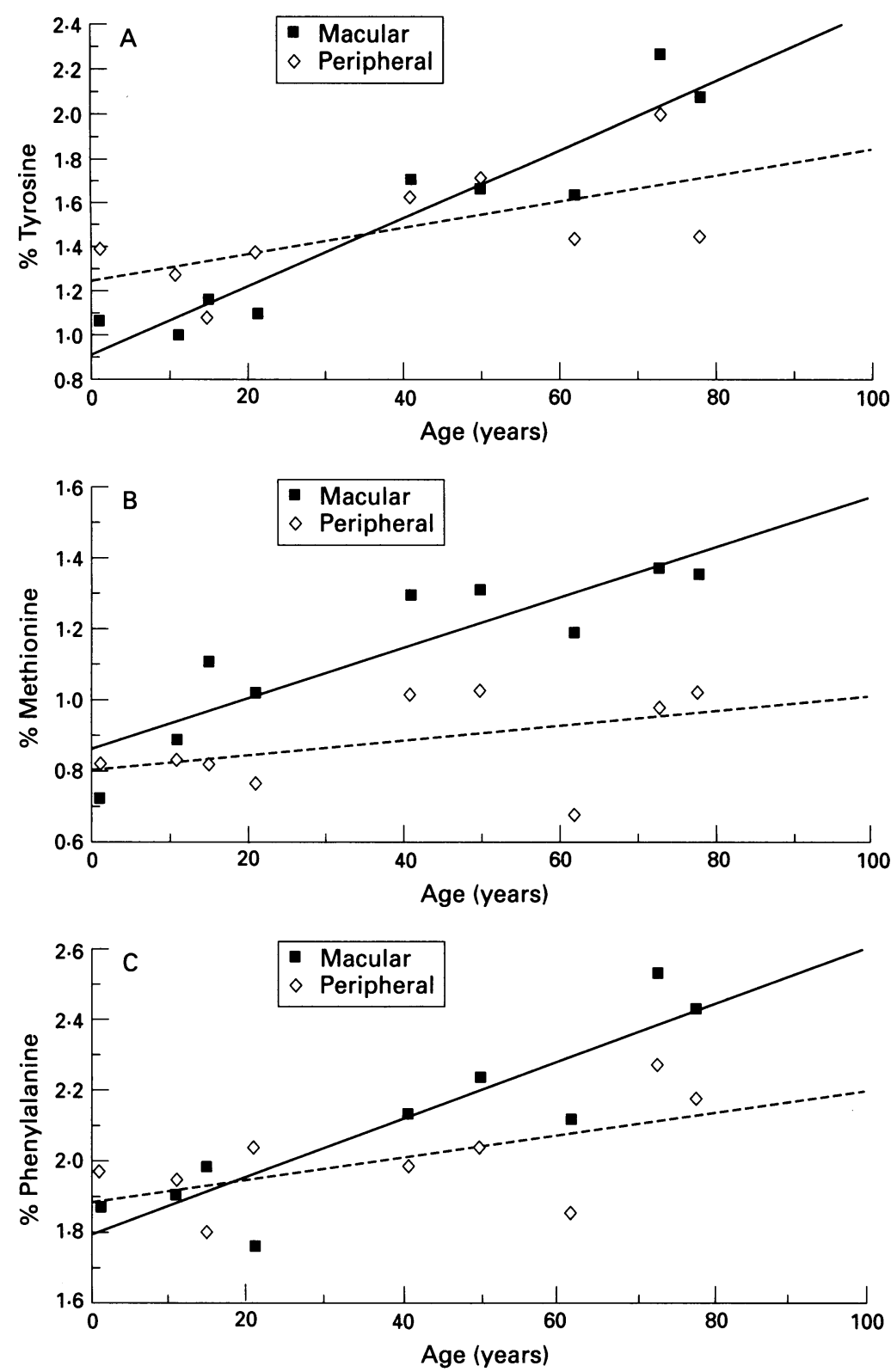

Figure 8 Proportion of $(A)$ tyrosine, $(B)$ methionine, and $(C)$ phenylalanine to total amino acids in Bruch's membrane from macular and peripheral regions as a function of age. methionine, as this residue was reduced before cyanogen bromide treatment, and so must be due to an increase in crosslinking. Similar decreases in collagen solubility are seen in other tissues. ${ }^{30}$ The enzymatically formed collagen crosslinks and their derivatives are known to link collagen molecules to stabilise the structure of the collagen fibres during deposition of the extracellular matrix. The absence of intermediate reducible crosslinks, which is expected in aging tissue, indicated their conversion to mature crosslinks, but these crosslinks, such as hydroxylysyl-pyridinoline, measured in our study, failed to show a significant increase with age, nor was there any detectable hystidinohydroxylysinonorleucine. The apparent crosslinking that causes the aggregation of the collagen and its decrease in solubility must be sought in as yet unknown additional crosslinks or by glycation crosslinks such as pentosidine. The presence of an unidentified amino acid in the 'crosslink' area of the chromatograph suggests a possible mechanism, which merits further study.

The consequences of the change in solubility may have an effect on the functioning of the membrane. It has previously been supposed that the membrane plays a passive role in the functioning of the choriocapillaris, RPE, and photoreceptor complex offering support but otherwise partaking little in the metabolism of the complex. However, early studies have indicated that Bruch's membrane may have a differential permeability to solutions of different solutes, ionic strengths, and $\mathrm{pH} .{ }^{31}$ Also experiments have shown that the permeability of the membrane to water decreases significantly with age. ${ }^{16}$ The passage of larger protein molecules can also be hindered by the membrane. ${ }^{31} 32$ Any change in the fluid permeability of the membrane could be due to either the increased crosslinking or increased deposition of lipid containing debris with age, or a combination of the two. Whether lipid deposition plays a significant role in the metabolism of the RPE is at present unclear but there is mounting evidence that it does so. ${ }^{510} \mathrm{It}$ is in this process of debris deposition that the changes in the nature of the collagen, a major component of Bruch's membrane, may play a crucial part. The crosslinking of the Bruch's membrane collagen may change the nature of the extracellular matrix such that it forms a network through which the debris is unable to pass with as great a facility in the old as in the young. This network could form a barrier to the passage of material in either direction. The build up of debris in Bruch's membrane with increasing age could be a consequence of this process. Alternatively, changes in the proteoglycan interfibrillary matrix of Bruch's membrane could be involved. ${ }^{18}$

A second consequence of increased crosslinking would be a decrease in the susceptibility of Bruch's membrane collagen to enzymatic action. The RPE is known to contain collagenolytic enzymes ${ }^{33-35}$ and crosslinking is known to reduce susceptibility to the enzymatic degradation of collagen. ${ }^{36}$ It is possible to envisage a situation where the already slow considerable decrease with age in samples taken both from the macular area and the periphery. This decrease appeared to be almost linear with age and by the ninth decade of life the solubility of collagen is less than $50 \%$. The decrease was not due to oxidation of 


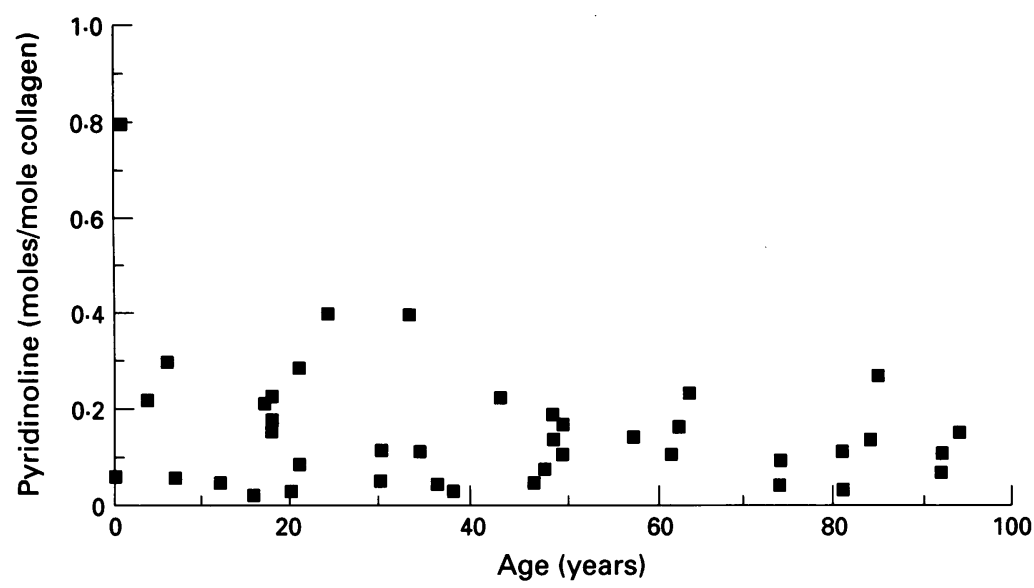

Figure 9 Hydroxylysyl-pyridinoline levels in Bruch's membrane.

turnover of Bruch's membrane collagen is further reduced by crosslinking of the collagen. A consequence of any decrease in membrane collagen turnover may be to allow more debris material to become lodged in the membrane.

Our results also indicate a significant decrease in the proportion of hydroxyproline and an increase in tyrosine, methionine, and phenylalanine in the macular region of Bruch's membrane with age. This was not seen in peripheral membrane. The increase in the amino acids low in collagen indicates an increase in the deposition of non-collagenous proteinaceous material in the membrane with age which is greater in the macular region than in the periphery. This quantitative finding is in agreement with the histological findings. ${ }^{37}$ The deposition of non-collagenous protein in Bruch's membrane with age is most likely to reflect debris material originating from the photoreceptors although deposition of membrane specific proteins or serum proteins cannot be excluded on present evidence.

We have shown that there are significant changes in the structure and content of the collagen of Bruch's membrane with age. It may be that an interaction of the changes in the matrix structure and the consequent functioning of the RPE produce changes that affect the metabolism of the RPE and secondarily that of the photoreceptors in the aging eye. Further studies of debris deposition and binding in Bruch's membrane, and of the nature of matrix change in aging membrane, may help elucidate

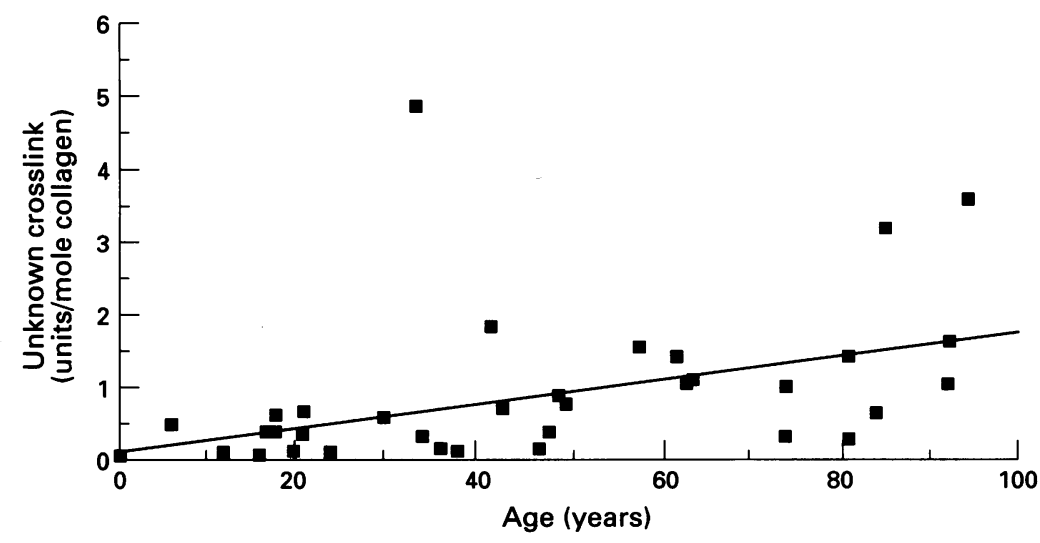

Figure 10 Levels of an unidentified putative collagen crosslink increase with age. the mechanisms behind age-related macular degeneration.

Support for this research was received from the Guide Dogs for the Blind Association and the National Eye Research Centre. We wish to thank Mr T J Sims for his help in the analysis of the collagen cross links, and $\mathrm{Mr} \mathrm{C}$ Voyle and $\mathrm{Mr} \mathrm{T}$ Cousins for their help with light and scanning electron microscopy.

1 Sarks SH. Aging and degeneration in the macular region: a clinicopathological study. $B r \not \mathcal{~ O p h t h a l m o l ~ 1 9 7 6 ; ~ 6 0 ~}$ 324-41.

2 Green WR, Key SN. Senile macular degeneration: a histopathological study. Trans Am Ophthalmol Soc 1977; 75: $180-250$.

3 Feeney-Burns L, Ellersieck $M$. Age related changes in the ultrastructure of Bruch's membrane. Am $\mathcal{f}$ Ophthalmol 1985; 100: 686-97.

4 Hogan MJ. Studies on the human macula. IV. Aging changes in Bruch's membrane. Arch Ophthalmol 1967; 77: 410-20.

5 Pauleikhoff D, Harper CA, Marshall J, Bird AC. Aging changes in Bruch's membrane: a histochemical and morphologic study. Ophthalmology 1990; 97: 171-8.

6 Farkas T, Sylvester V, Archer D. The ultrastructure of drusen. Am 7 Ophthalmol 1971; 71:1196-205.

7 Farkas T, Sylvester V, Archer D, Altona M. The histochemistry of drusen. Am $\mathcal{F}$ Ophthalmol 1971; 71: 1206-15.

8 Hogan MJ. Role of the retinal pigment epithelium in macular disease. Trans Am Acad Otolaryngol Ophthalmol 1972, 76: $64-80$.

9 Grindle CFJ, Marshall J. Aging changes in Bruch's membrane and their functional implications. Trans Ophthalmol Soc UK 1978; 98: 172-5.

10 Bird AC. Bruch's membrane change with age. $\mathrm{Br} f$ Ophthalmol 1992; 76: 166-8.

11 Killingsworth MC. Age-related components of Bruch's membrane in the human eye. Graefes Arch Clin Exp Ophthalmol 1987; 225: 406-12.

12 Newsome DA, Hewitt AT, Huh W, Robey PG, Hassell JR Detection of specific extracellular matrix molecules in drusen, Bruch's membrane, and the ciliary body. $A m \mathcal{F}$ Ophthalmol 1987; 104: 373-81.

13 Campochiaro PA, Jerdan JA, Glaser BM. The extracellular matrix of human retinal pigment epithelial cells in vivo and its synthesis in vitro. Invest Ophthalmol Vis Sci 1986; 27: 1615-21.

14 Das A, Frank RN, Zhang NL, Turczyn TJ. Ultrastructural localization of extracellular components in human retinal localization of extracellular components in human retinal vessels and

15 Marshall GE, Konstas AGP, Reid GG, Edwards LG, Lee WR. Type IV collagen and laminin in Bruch's membrane and basal laminar deposit in the human macula. $B r f$ Ophthalmol 1992; 76: 607-14.

16 Fisher RF. The influence of age on some ocular basement membranes. Eye 1987; 1: 184-9.

17 Robey PG, Newsome DA. Biosynthesis of proteoglycans present in primate Bruch's membrane. Invest Ophthalmol Vis Sci 1983; 24: 898-905.

18 Hewitt AT, Nakazawa K, Newsome DA. Analysis of newly synthesized Bruch's membrane proteoglycans. Invest synthesized Bruch's membrane prot
Ophthalmol Vis Sci 1989; 30: 478-86.

19 Miller EJ, Rhodes RK. Preparation and characterization of the different types of collagen. Methods Enzymol 1982; 82: 33-64.

20 Laemmli UK. Cleavage of structural proteins during assembly of the head of bacteriophage T4. Nature 1970; 227: $680-5$.

21 Light ND. Estimation of Types I and III collagens in whole tissue by quantitation of $\mathrm{CNBr}$ peptides on SDS-polyacrylamide gels. Biochim Biophys Acta 1982; 702: 30-6.

22 Light N D, Bailey A J. Covalent cross-links in collagen. Methods Enzymol 1982; 82: 360-72.

23 Sims TJ, Bailey AJ. Quantitative analysis of collagen and elastin cross-links using a single-column system. f Chromatogr 1992; 582: 49-55.

24 Timpl R, Bruckner P, Fietzek P. Characterization of pepsin fragments of basement membrane collagen from a mouse tumor. F Biochem 1979; 95: 255-63.

25 Turksen K, Opas M, Aubin JE, Kalnins VI. Microtubules, microfilaments and adhesion patterns in differentiating chick embryo retinal pigment epithelial cells in vitro. Exp Cell Res 1983; 147: 379-91.

26 Goldbaum MH, Madden K. A new perspective on Bruch's membrane and the retinal pigment epithelium. Bruch's membrane and the retinal

27 Mays PK, Bishop JE, Laurent GJ. Age-related changes in the proportion of types I and III collagen. Mech Ageing

28 Viidik A, Danielsen CC, Oxlund H. On fundamental and phenomenological models, structure and mechanical properties of collagen, elastin and glycosaminoglycan complexes. Biorheology 1982; 19: 437-51.

29 Burgeson RE. The collagens of skin. Curr Probl Dermatol 1987; 17: 61-75.

30 Bailey AJ, Robins SP, Balian G. Biological significance of the intermolecular crosslinks of collagen. Nature 1974; 251: 105-9.

31 Lyda W, Eriksen N, Krishna N. Studies of Bruch's membrane. Flow and permeability studies in a Bruch's membrane-choroid preparation. Am 7 Ophthalmol 1957; 44: $362-70$. 
32 Pino RM, Essener E. Permeability of rat choriocapillaris to hemeproteins. Restriction of tracers by a fenestrated endothelium. F Histochem Cytochem 1981; 29: 281-90. 33 Hayasaka $S$. Lysosomal enzymes in ocular tissues and diseases. Surv Ophthalmol 1983; 27: 245-58.

34 Alexander JP, Bradley JMB, Gabourel JD, Ascott TS. Expression of matrix metalloproteinases and inhibitor by human retinal pigment epithelium. Invest Ophthalmol Vis human retinal pigment $1990 ; 31: 2520-8$.
35 Karwatowski WSS, Smith ES, Mackiewicz R. Variation in proteolytic activity of macular and peripheral retinal pigment epithelial cells as a function of age. Invest Ophthalmo Vis Sci 1992; 33: 909.

36 Vater CA, Harris ED, Siegel RC. Native cross-links in collagen fibrils induce resistance to human synovial collagenase. Biochem f 1979; 181: 639-45.

37 Sarks SH. Drusen and their relationship to senile macular degeneration. Austral f Ophthalmol 1980; 8: 117-30. 